\title{
Arnaud de Salette, Los psalmes de David metuts en rima bernesa
}

\section{Michele Mastroianni}

\section{(2) OpenEdition}

1 Journals

\section{Edizione digitale}

URL: http://journals.openedition.org/studifrancesi/5583

DOI: $10.4000 /$ studifrancesi.5583

ISSN: 2421-5856

\section{Editore}

Rosenberg \& Sellier

\section{Edizione cartacea}

Data di pubblicazione: 1 septembre 2011

Paginazione: 398

ISSN: 0039-2944

\section{Notizia bibliografica digitale}

Michele Mastroianni, «Arnaud de Salette, Los psalmes de David metuts en rima bernesa», Studi Francesi [Online], 164 (LV | II) | 2011, online dal 30 novembre 2015, consultato il 12 janvier 2021. URL: http:// journals.openedition.org/studifrancesi/5583 ; DOI: https://doi.org/10.4000/studifrancesi.5583

Questo documento è stato generato automaticamente il 12 janvier 2021.

\section{(c) (i) (9)}

Studi Francesi è distribuita con Licenza Creative Commons Attribuzione - Non commerciale - Non opere derivate 4.0 Internazionale. 


\title{
Arnaud de Salette, Los psalmes de David metuts en rima bernesa
}

\author{
Michele Mastroianni
}

\section{NOTIZIA}

ARNAUD DE SALETTE, Los psalmes de David metuts en rima bernesa, édition critique bilingue par Robert DARRIGRAND, sur le texte de l'édition publiée en 1583 à Ortez par Louis Rabier, introduction, notes et traduction par Robert DARRIGRAND, présentation par Philippe CHAREYRE, Paris, Champion, 2010 («Textes Littéraires de la Renaissance», 3), 970 pp.

1 Robert Darrigrand, ispanista, linguista e studioso della Riforma nel Béarn, offre l'edizione critica (la prima edizione moderna), accompagnata da una traduzione a fronte, del salterio tradotto in volgare bearnese da Arnaud de Salette, su richiesta della regina di Navarra, Jeanne d'Albret, nel quadro di un vasto progetto di riduzione alla Riforma del suo stato. Tale volgarizzamento è libero adattamento dei testi del Salterio di Ginevra, opera di Clément Marot e Théodore de Bèze, testi di cui riprende anche la mise en musique. La presente edizione interessa anzitutto gli storici della lingua, in particolare gli studiosi della langue d'oc, cui viene fornito un ricco studio dei problemi linguistici, con considerazioni sul bearnese del Cinquecento e sui suoi rapporti col francese (in particolare sui gallicismi). Ma l'introduzione fornisce anche una serie di dati utili allo studioso della Riforma nell'area francese, illustrando alcuni aspetti culturali della creazione del culto riformato e la dialettica che si instaura, in questo campo, fra tendenza al regionalismo e tendenza alla francesizzazione. 